\title{
Optimization of Ligand Surface Concentration for Biosensor based on Imaging Ellipsometry
}

\author{
Yu Niu ${ }^{1,2}$, Gang Jin ${ }^{1, *}$ \\ ${ }^{1}$ Institution of mechanics, Chinese academy of Sciences, Beijing, China. \\ ${ }^{2}$ Graduate University of Chinese academy of Sciences, Beijing, China. \\ ${ }^{*}$ Corresponding author: Tel./Fax.: +86-10-82544138, E-mail: gajin@imech.ac.cn
}

\begin{abstract}
- the biosensor based on imaging ellipsometry for bio-molecular interactions has been developed for more than ten years and used to several biological applications successfully, such as detection of five markers of Hepatitis B, tumor markers and virus infection. Ligand surface concentration which might be related with its spatial configuration and bioactivity is an important factor to affect the biosensor sensitivity and dynamic range. In this investigation, IgG and its corresponding antibody are selected as a couple of model molecules for the optimization of ligand surface concentration. The optimization result of ligand surface concentration is achieved by analyzing the surface concentration increase of antigenantibody complex on sensing surface with various ligand surface concentrations.
\end{abstract}

Keywords-biosensor, protein micro-array, Imaging ellipsometry, ligands surface concentration.

\section{INTRODUCTION}

The concept of biosensor based on imaging ellipsometry for visualization of bio-molecular interactions was proposed in 1995 [1]. Imaging ellipsometry which has the advantages of ellipsometry and microscopy simultaneously is used to measure the amount of protein in an adsorbed layer accurately without any labeling [2]. This allows the application in a broad range of various biological systems, especially for the detection of interactions between protein molecules $[3,4]$. So far, several bio-molecules, like five markers of Hepatitis B, Tumor markers, and Virus, have been tested successfully with the biosensor [5-7].

Ligand surface concentration is intimately associated with the amount of complex formation, and consequently, it has been proved that a remarkable factor can influence the biosensor sensitivity and dynamic range. In common sense, the amount of captured target bio-molecule might be proportional to the surface concentration of ligand, so the ligand surface concentration is usually used at its saturation level. However, the phenomenon is observed through the interaction between Bovine serum albumin (BSA) and its corresponding antibody that the surface concentration of BSA/anti-BSA binding complex rises firstly and then de- clines, as the surface concentration of BSA simply increases [8]. It is suggested that ligand surface concentration at its saturation may not be the optimization result.

In this investigation, $\operatorname{IgG}$ and its corresponding antibody, as a couple of model molecule are studied to optimize the ligand surface concentration.

\section{MATERIALS AND METHODS}

\section{A. Principles}

The label-free biosensor which functions as a kind of immunoassays is composed of two parts, micro-fluidic reactor system and Imaging ellipsometry reader.

A 48 channel integrated micro-fluidic reactor system which is served as micro-reactor system can be used to fabricate protein micro-array for high throughput detection [5]. By this reactor, ligands could be delivered individually to each unit and covalently immobilized on surface simultaneously to form ligands with a fixed pattern. After that, these ligands with good bioactivity can be reacted with different analytes under dynamic condition. During the whole process, the protein micro-array is stored in the packaging system which is full of buffer so that proteins are not exposed to denaturing conditions.

With a visualization of imaging ellipsometry, which has a high spatial resolution in the order of sub-nanometer in vertical and micron in lateral, the changes of surface concentration which is resulted from the interaction between ligand and analyte can be determined sensitively and accurately. The results of imaging ellipsometry shown in gray scale were processed to be the surface concentration of the adsorption layer.

\section{B. Reagents and solutions}

Chemicals used for PBS buffer $(\mathrm{pH}=7.4)$ preparation were all of analytical grade or better. Aminopropyltriethoxysilane (APTES) were purchased from Acros Organics. Succinic anhydride was purchased from Beijing hengye zhongyuan chemical Co., Ltd. 1-(3-Dimethylaminopropyl)- 
3-ethylcarbodiimide hydrochloride (EDC) and N- hydroxydroxysuccinimide (NHS) were purchased from Sigma. RatIgG and Anti-Rat-IgG antibody were purchased form Sigma.

\section{Substrates}

Silicon wafer was used as solid surface for imaging ellipsometry biosensor. Due to the need of 48 throughputs, the silicon slides were cut into $25 \times 13 \mathrm{~mm} 2$ rectangle pieces. Then, aiming at washing out the organic and inorganic pollution, silicon wafers were cleaned with a mixture of $30 \%$ $\mathrm{H} 2 \mathrm{O} 2$ and concentrated $\mathrm{H} 2 \mathrm{SO} 4(1: 3 \mathrm{v} / \mathrm{v})$ for 30 minutes [9]. After thoroughly rinsing with deionized water and pure ethanol, these silicon wafers were treated with an ethanol solution of APTES (5\% APTES and 95\% pure ethanol) and the incubation last 2 hours at room temperature [10]. Following by intensively rinsing with pure ethanol, the silicon wafers silanized with APTES were reacted with oversaturated succinic anhydride in ethanol for at least 3 hours. After the final rinsing with pure ethanol, the silicon wafers were stored in pure ethanol for ligands immobilization.

\section{D. $\operatorname{Ig} G$ adsorption and $\operatorname{Ig} G /$ Anti-IgG interaction}

Surface concentration of IgG adsorption is intimately associated with IgG solution concentration, so several surface concentration of $\operatorname{IgG}$ can be achieved by controlling the solution concentration. In order to form significant variation among surface concentration of IgG adsorption, IgG solution is diluted with PBS buffer to $0.004 \mathrm{mg} / \mathrm{mL}$, $0.016 \mathrm{mg} / \mathrm{mL}, \quad 0.064 \mathrm{mg} / \mathrm{mL}, \quad 0.25 \mathrm{mg} / \mathrm{mL}, \quad 1 \mathrm{mg} / \mathrm{ml}$ and $4 \mathrm{mg} / \mathrm{mL}$, respectively. IgG diluted solution at each concentration is used in four units in which two for analyte test and others as negative control.

The whole processes are listed as follows: Firstly, the modified surface is incubated with a mixture solution of EDC and NHS at the concentration of $0.2 \mathrm{~mol} / \mathrm{L}$ and $0.05 \mathrm{~mol} / \mathrm{L}$ for 5 minutes. In order to lessen the impact caused by non-specific adsorption, a step of blocking by Gelatin follows that IgG is immobilized to form a sensing surface with different surface concentration. The anti-IgG antibody solutions at $0.01 \mathrm{mg} / \mathrm{mL}$ and $0.2 \mathrm{mg} / \mathrm{mL}$ are delivered and react with $\mathrm{IgG}$ ligands on sensing areas.

\section{Results}

IgG at different surface concentration is assembled on the substrate, and then is exposed to Anti-IgG solution at the concentration of $0.01 \mathrm{mg} / \mathrm{mL}$ and $0.2 \mathrm{mg} / \mathrm{mL}$. With a visualization of imaging ellipsometry, the surface concentration of the adsorption layer can be quantitatively shown in gray scale. After a logarithmic transformation of $\operatorname{IgG}$ solution concentration, the surface concentration trends of IgG adsorption and complex are present in Fig.1.

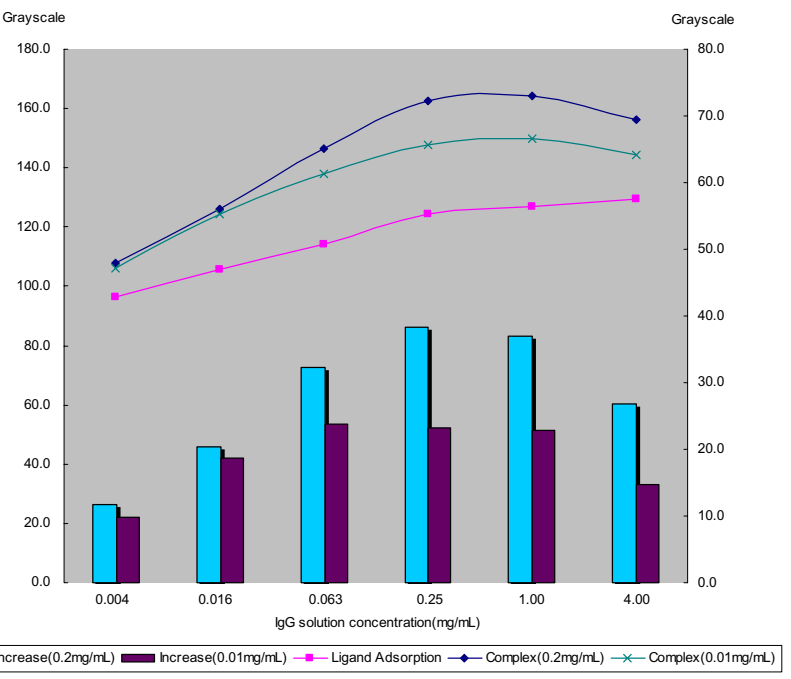

Fig. 1 the results of IgG adsorption and IgG/anti-IgG binding complex

The surface concentration of $\operatorname{IgG}$ adsorption increases with the rise of its solution concentration but the increasing rate decreases when IgG solution concentration is beyond $0.25 \mathrm{mg} / \mathrm{mL}$. The trend suggests that the amount IgG adsorption approaches to saturation when its solution concentration is beyond $0.25 \mathrm{mg} / \mathrm{mL}$.

Unlike the trend of IgG adsorption, when solution concentration of Anti-IgG antibody is select at $0.01 \mathrm{mg} / \mathrm{mL}$, the surface concentration of $\mathrm{IgG} / \mathrm{Anti}-\mathrm{IgG}$ complex firstly goes up dramatically and then declines slightly, while the maximum is at the $\mathrm{IgG}$ solution concentration of $1.0 \mathrm{mg} / \mathrm{mL}$. However, the increase which can reflect the amount of binding antibody displays different trend. Firstly, the increase rises as solution concentration grows from $0.004 \mathrm{mg} / \mathrm{mL}$ to $0.016 \mathrm{mg} / \mathrm{mL}$. Then, it keeps steady when solution concentration increases from $0.064 \mathrm{mg} / \mathrm{mL}$ to $1.0 \mathrm{mg} / \mathrm{mL}$. Finally, it decreases sharply at solution concentration of $4.0 \mathrm{mg} / \mathrm{mL}$. The same trend repeats when anti-IgG antibody is selected at $0.2 \mathrm{mg} / \mathrm{mL}$, but the increase begins to remain steady at solution concentration of $0.25 \mathrm{mg} / \mathrm{mL}$.

In order to improve sensitivity and dynamic range of the biosensor, the surface concentration of ligand should be optimized at the point where the IgG/Anti-IgG binding complex reaching to the maximum. Therefore, when antiIgG solution concentration is at $0.01 \mathrm{mg} / \mathrm{mL}$ and $0.2 \mathrm{mg} / \mathrm{mL}$, the optimization range of $\mathrm{IgG}$ solution concentration should be from $0.064 \mathrm{mg} / \mathrm{mL}$ to $1.0 \mathrm{mg} / \mathrm{mL}$ and from $0.25 \mathrm{mg} / \mathrm{mL}$ to $1.0 \mathrm{mg} / \mathrm{mL}$, respectively. It is obviously indicated that optimization surface concentration of ligand may change ac- 
cording to analyte at different concentration. Furthermore, the surface concentration optimized by analyte at higher concentration is involved in the range which is achieved by lower concentration and can be applied under the condition of lower analyte concentration test.

In the condition that $\mathrm{IgG}$ surface concentration is at $4.0 \mathrm{mg} / \mathrm{mL}$, a sharp drop of the amount of binding antibody comes to both concentrations of Anti-IgG antibody. It can be foreseen that ligand surface concentration approaching to saturation may change its spatial configuration, cause steric exclusion and decrease its bio-activity. Meanwhile, rinsing process may affect more when ligand surface concentration is approaching saturation. Therefore, ligand surface concentration should be optimized below saturation adsorption concentration.

\section{Conclusions}

The optimizing ligand surface concentration should be lower than the saturation adsorption concentration; meanwhile, comparing to analyte at lower concentration, the result optimized by higher analyte concentration owns a wider application scope.

\section{ACKNOWLedgment}

The Chinese Academy of Sciences KJCX2-YW-M03 and KJCX2-YW-M04, National Basic Research Program of
China 2009CB320302 and "863" program is acknowledged for financial supports.

\section{REFERENCES}

1. Jin G, Tengvall P, Lundstrom I, et al. (1995) A biosensor concept based on imaging ellipsometry for visualization of biomolecular interactions. Anal. Biochem. 232:69-72.

2. Jin G, Jansson R, Arwin H (1996) Imaging ellipsometry revisited Developments for visualization of thin transparent layers on silicon substrates. Rev. Sci. Instrum. 67:2930-2936.

3. Jin G, Wang Z H (2002) Micro-systems for optical protein-chip. International Journal of Nonlinear Sciences and Numerical Simulation 3:191-194.

4. Wang Z H, Jin G (2003) A label-free multisensing immunosensor based on imaging ellipsometry. Anal. Chem. 75:6119-6123.

5. Wang Z H, Meng Y H, Ying P Q et al. (2006) A label-free protein microfluidic array for parallel immunoassays. Electrophoresis 27:4078-4085.

6. Qi C, Duan J Z, Wang Z H et al. (2006) Investigation of interaction between two neutralizing monoclonal antibodies and sars virus using biosensor based on imaging ellipsometry. Biomed. Microdevices $8: 247-253$.

7. Jin G (2008) Development of biosensor based on imaging ellipsometry. Physica Status Solidi A: Applications and Materials Science 205:810-816.

8. Ying P Q, Jin G, Tao Z L (2004) Competitive adsorption of collagen and bovine serum albumin - effect of the surface wettability. Colloids and Surfaces B: Biointerfaces 33:259-263.

9. Wang Z H, Jin G (2003) Feasibility of protein A for the oriented immobilization of immunoglobulin on silicon surface for a biosensor with imaging ellipsometry. J. Biochem. Biophys. Methods 57:203211.

10. Wang Z H, Jin G (2004) Covalent immobilization of proteins for the biosensor based on imaging ellipsometry. J. Immunol. Methods 285:237-243 